\title{
Lif Katkılı Betonlarda Fiber Oranının Basınç Dayanımına Etkisinin Deneysel ve Nümerik İncelenmesi ${ }^{1}$
}

\author{
Mohammad Manzoor Nasery², Elif Ağcakoca ${ }^{3 *}$, Zeynep Yaman ${ }^{4}$
}

Geliş / Received: 25/03/2020

Revize / Revised: 02/11/2020

Kabul / Accepted: 03/11/2020

\begin{abstract}
$\overline{\mathbf{O Z Z}}$
Günümüzde hızla gelişen teknolojinin sonucu olarak, insanların daha rahat yaşam bulabilecekleri kentsel yaşamı tercih etmeleri, betonarme çok katlı yapı kültürünün hâkim olduğu kentlerde, doğal afetin etkisine karşı yeterli dayanıma sahip yapı inşa etme arayışını beraberinde getirmektedir. Özellikle yüksek katlı yapılarda kullanılan malzemelerden beklenen yüksek dayanım ve kullanılabilirlik, inşaat sektörünü yeni teknolojiler ile üretilmiş malzeme arayışına yönlendirmektedir. Son yıllarda iki veya daha fazla sayıda, aynı veya farklı gruptaki malzemelerin üstün özellikleri kullanılarak oluşturulmuş kompozit elemanlar, inşaat sektörü alanına yeni bir bakış açısı kazandırmıştır. Bu malzemelerin başında mühendisliğin hertürlü alanında geniş kullanıma sahip fiber malzeme gelmektedir. Özellikle beton içine uygulanan, fiber donatı olarak tanımlanan malzeme, püskürtme veya saha betonuna süneklik özelliği kazandırmaya çalışılmaktadır. Genel olarak literatürde ve pazarlamaya yönelik ARGE laboratuvarlarında fiber donatı takviyeli betonun, eğilme etkisi altındaki davranışı incelenmekte olduğu gözlenmiştir. Bu nedenle bu çalışmada fiber donatılı takviye edilmiş betonun, eksenel basınç etkisi altındaki yapı elemanlarında kullanılması durumunda sergileyeceği davranış incelenmiştir. Yapılan deneysel çalışmada, beton karışım içine ilave edilen farklı oranda fiber ile dört farklı beton sınıfından üretilen on iki adet silindirik numune üzerinde eksenel basınç deneyleri yapılmıştır. Çalışma kapsamında; farklı dayanıma sahip beton numunelere, farklı oranda fiber ilave edilmesinin, beton basınç dayanımı üzerine olan etkileri incelenmiştir. Ayrıca çalışmada beton numunelerinin sonlu eleman modeli, Beton Plastikleşme Hasar Modeli yardımıyla hazırlanmıştır. Sonrasında, Abaqus/Standart sonlu eleman programı kullanarak numeneler analiz edilmiş ve deneysel veriler ile karşılaştırılarak sonlu eleman programı doğrulanmıştır.
\end{abstract}

1Sunulan makale 4-6 Mayıs 2018 tarihinde gerçekleștirilen "2nd International Symposium on Natural Hazards and Disaster Management" sempozyumunda sunulan bildiri geliștirilerek hazırlanmıștır.

2İletişim: manzoor.nasery@gmail.com (https://orcid.org/0000-0003-3787-1355)

İnşaat Mühendisliği, Karadeniz Teknik Üniversitesi, 61080, Trabzon, Türkiye

3*Sorumlu yazar iletişim: elifd@sakarya.edu.tr (https://orcid.org/0000-0001-8228-0592)

Inş̧aat Mühendisliği, Sakarya Üniversitesi, Esentepe Kampüsü, Sakarya, Türkiye

4İletişim: zdyaman@sakarya.edu.tr ( https://orcid.org/0000-0003-0987-6685)

Inşaat Mühendisliği, Sakarya Üniversitesi, Esentepe Kampüsü, Sakarya, Türkiye 


\title{
Experimental and Numerical Investigation of the Effect of Fiber Reinforcement on Compressive Strength in Fiber Reinforced Concrete
}

\begin{abstract}
Today, as a result of the rapidly developing technology, people prefer urban living environments where they can find a more comfortable life, as well as seeking to build a structure that is sufficiently resistant to the effect of dynamic loads, in addition to all kinds of natural disasters in cities where reinforced concrete (RC) multi-stores building type is dominant. The high strength and usability expected from the materials used in high-rise buildings direct us to the search for materials produced with new technologies. Especially in recent years, composite elements created by using superior properties of two or more materials of the same or different groups have given a new perspective to the construction sector. One of these materials is fiber material, which has wide usage in engineering field. It is tried to gain mechanical properties such as elasticity and ductility to concrete used in spraying or on-site concrete applications with the material defined as fiber reinforcement especially in concrete. In general, it has been observed that the mechanical properties of fiber reinforced concrete in bending effect are examined in the literature and R\&D laboratories for marketing. To this end, in the study, the mechanical behaviors of fiber reinforced concrete in case of use in the structural elements under the influence of axial pressure are examined. In the experimental study, concrete pressure tests were carried out on twelve cylindrical samples produced from four different concrete classes with a different proportion of fiber added to the concrete mixture. Scope of work, the effects of adding a different proportion of fiber to concrete samples with different strength on concrete compressive strength was investigated. In addition, the finite element model of the concrete samples was analyzed with the help of the Abaqus / Standard finite element program using the Concrete Plasticization Damage Model and verified by comparison with the experimental results data.
\end{abstract}

Keywords- Concrete, Fiber Rebar, Composite, Finite Element Model, Axial Compressive 


\section{GİRIŞ}

Çimento malzemesinin 19. yüzyılın başlarından itibaren fabrika ortamında üretilmeye başlanması ile beton malzemesi yapılarda yaygın olarak kullanılmaya başlanmıştır. Beton, içerisinde yaklaşık \%10 oranında çimento, \%75 oranında agrega (kum, çakıl, kırma taş), \%15 oranında su (çimento ağırlığının \%2 sinden fazla olmamak üzere), katkı maddelerinin uygun oranlarda ve koşullarda karıştırılması ile oluşturulan kompozit bir yapı malzemesidir [1]. Her yapı malzemesinde olduğu gibi kompozit yapı malzemeleri de mekanik özellikleri esas alınarak tanımlanmakta ve sınıflandırılmaktadır. Beton sınıflandırılırken, betonun en önemli özelliği olan basınç dayanımı dikkate alınmaktadır. Yapı elemanların oluşturulmasında betonun yaygın bir şekilde tercih edilmesinin en önemli nedeni, yüksek basınç mukavemeti ve farkı hava şartlarına karşı diğer yapı malzemelerinden daha dayanıklı olmasıdır.

Büyük şehirlerde nüfusun belirli bölgelerde toplanması, yapıların yüksek katlı olması ihtiyacını ortaya çıkarmış, teknolojinin ilerlemesiyle bu tür ihtiyaçları karşılamak için inşaat sektörü de çözüm arayışına girmiştir. Özellikle yüksek katlı binalarda, yapıya etkiyen tüm riskli yükleme durumları belirlenerek, çekme ve basınç dayanımı yüksek, yeni nesil malzeme kullanması tercih edilebilmektedir. Yapılara etkiyen yüklere karşı yapının taşıma gücünü artırmak için, farklı yapı sistemleri ve dayanımı artırılmış farklı malzemelerin oluşturduğu kompozit elemanlar kullanılabilmektedir. Özellikle yüksek katlı modern yapılarda çok yaygın olarak, betonun dayanımının arttırılması talebi, sektörü malzeme konusunda yeni arayışlara yönlendirmektedir [2].

Beton dayanımının artırılmasına yönelik olarak üretilen yeni nesil bir malzeme olan fiber (lif) donatı takviyesi özellikle saha betonu uygulamalarında yaygın olarak kullanılmaktadır. Fiber donatı olarak tanımlanan lif malzemelerin, cam lif, karbon lif, poliamid lif gibi türevleri bulunmaktadır. Bu çalışmada, ham madde olarak poliamid malzeme kullanılarak üretilmiş sentetik fiber, farklı oranlarda ve farklı basınç dayanımlarına sahip beton karışımlar içine konularak, oluşturulan yeni kompozit elemanın beton basınç dayanımında meydana getirdiği değişim incelenmiştir. Ayrıca sonlu eleman çözümünden elde edilen veriler, deneysel veriler ile karşılaştırılarak doğrulanmıştır.

\section{LITERATÜR ÇALIŞMASI}

Mevcut çalıșmalarda; farklı beton sınıfına sahip beton numunelerine ve farklı oranda çelik lif takviye edilerek oluşturulan numunelerinin, basınç ve eğilme kuvveti etkisi altındaki dayanımı incelenmiştir [3]. Benzer çalışmada, \%0,2-\%0,6 arasında değişen oranda cam lif takviye edilen silindir geometriye sahip beton boruların taşıma gücü deneysel olarak araştırılmıştır. Eksenel basınç deneyi sonucunda; lif oranı artıkça, elemanın deplasman değeri artmış, elemanda kopma ve kırılmalar olmadan daha fazla yük taşıdığı belirlenmiştir [4]. Çelikten (2014) tarafından gerçekleştirilen çalışmada; yüksek dayanımlı betona çelik lif ilave edilerek, çelik lifin yüksek dayanımlı beton davranışına olan etkisi araştırılmıştır. Fiber kullanarak yüksek basınç dayanımı, süneklik ve tokluk değerlerini elde etmek için, yüksek performansa sahip karma lif içeren çimento esaslı kompozit elemanlar üretilmiştir. Ayrıca karma lif ilavesinin, kompozit eleman dayanımında oluşturduğu mekanik değişim incelenmiştir [5]. Avar (2006) çalışmasında; çelik liflerin kanca uçlu olan veya olmayan olarak üç farklı türünün eleman dayanımına olan etkisini incelemiştir [6]. Bir başka çalışmada, kare geometriye sahip dik katmanlı plak elemanları elyaf ile takviye edilmiş, elemanda oluşan serbest titreşim değerleri incelenmiştir. Ayrıca farklı uzunluktaki elyaf takviyesinin eleman davranışı üzerine olan etkileri de araştırılmıştır. Analiz sonuçları, elyaf malzemesinin mekanik özelliklerinin plak elemanın davranışı üzerine etkili olduğu görülmüsşür [7]. Eren (2016); fiber malzeme kullanılarak üretilmiş kumaşların son yıllarda inşaat mühendisliği alanındaki kullanımını alanlarını incelemiştir. Çalışma sonucunda, uygulamada karşılaşılan sorunlar incelenmiş ve çözüm yöntemleri ilgili alternatifler sunulmuştur [8]. Ağcakoca (2020) tarafindan aramid içerikli lif ile güçlendirilmiş çelik elemanların darbe yükü etkisi altındaki davranışı incelenmiş, inşaat sektöründe lifli malzeme ile güçlendirilmiş elemanların faydaları üzerinde durulmuştur [9]. Hüsem (2013); çelik ve polipropilen içerikli lif katkısı kullanarak düşük ve yüksek dayanıma sahip beton olarak üretilmiş kompozit elemanların basınç ve çekme dayanımlarını araştırmış, zarar görmüş beton numunelerde oluşan kırılma ve çatlak değişimleri incelemiştir [10]. Lif takviye edilerek üretilmiş polimerlerin fiziksel ve mekanik özellikleri Özşahin (2015) tarafından irdelenmiş, ayrıca lif takviye edilerek üretilmiş polimerlerin betonarme elemanlarda donatı elemanı olarak kullanımını incelenmiştir [11]. Çelik (2014); silindir geometriye sahip beton numuneleri lif içerikli karbon elyaf malzemesi ile sararak güçlendirmiş, tekrarlı eksenel basınç kuvveti uygulanmış ve karbon elyaf sarma sayısının numunenin basınç dayanımına etkisini 
incelemiştir [12]. Taşdemir (2012); yüksek ve ultra yüksek dayanımlı betonlarda yutulan bağıll enerjinin düşük olmasından hareketle, yüksek dayanımlı betonlara kısa kesilmiş çelik teller ekleyerek, elemanın sünek davranışa sahip olması üzerine deneysel bir çalışma yapmıştır [13]. Kim 2015 yılında yaptığı çalışmada; demet tipi poliamid fiber ve çengel uçlu fiber takviyesi ile üretilen beton numunelerde, yüksek hızlı çarpma yükü etkisi ile gerçekleşen kırılma davranışları, penetrasyon derinliği, oluşan krater çapı açısından incelemeler yapmış ve demet tipi poliamid fiberlerin bağlanma mukavemetini ve eğilme özelliklerini çengel uçlu çelik fiberlerinkiyle karşılaştırmıştır. Demet tipi poliamid fiberlerin, artan interfiber boşluk ve bağlanma için fiber çekmesi olmadan kırılmaya maruz kaldığını, ancak çengel uçlu çelik fiberlere kıyasla daha düşük spesifik yüzey alanı nedeniyle eğilme mukavemeti ve kırılma enerjisi ile daha zayıf eğilme kırığı davranışı sergilediğini tespit etmiştir [14]. 2019 yılında yaptığı çalışmada ise demet tipi poliamid elyaf takviyeli çimentolu kompozit ve çengel çelik elyaf takviyeli çimentolu kompozitin sıkıştırma ve çekme davranışları üzerindeki gerilme oranı etkisini değerlendirmiştir. Sonuçlar; şekil değiştirme hızı, kırılma davranışı, mekanik bağ,lanma kuvvetindeki değişimler açısından irdelenmiştir [15]. Yıldızel (2020) çalışmasında, cam elyaf ile güçlendirilmiş endüstriyel beton ve duvarların üretilmelerine yardımcı olmak için genel tasarım optimizasyonu yapmıştır. Agrega metakaolin (MK) ve GF içerikleri olarak kullanılan macun ve silis kumu dahil olmak üzere bileşenlerin basınç ve eğilme mukavemetleri açısından etkilerini incelenmiştir. İşlenebilirlik gibi taze beton özellikleri lif içeriği testleri ile araştııılmıştır. Optimum içerik muhtevası ve bunların beton performansı ile ilişkileri Taguchi, ANOVA ve ekstrem vertices tasarım yöntemlerinin birlikte kullanılmasıyla belirlenmiş̧ir [16]. Silindir geometriye sahip siloların fiber içerikli şerit kullanarak, burkulma [17] ve hidrostatik basınç [18] etkisi altındaki davranışları incelenmiştir. Yapı elemanlarına imalat aşamasında fiber ilave edilerek dayanımı artırılabildiği gibi, kolon kiriş birleşim yerlerinde farklı bağlantı elemanları kullanarak dayanımda artış sağlanmakta [19], bu bağlantılar yapının modal parametrelerinde farklılıklar yaratmaktadır [20].

\section{MATERYAL VE YÖNTEM}

Deneysel çalışmada, beton malzemesine fiber ilave edilerek elde edilen kompozit elemanın basınç etkisi altındaki davranışı incelenmiştir. Kompozit eleman oluşturulurken fiber donatı kullanılmıştır. Fiber malzeme Poliamid 6.6 hammaddesinden EN 14889-2 [21] Sinıf 1 ve ASTM C 1116 [22] standartlarına göre üretilen, sentetik malzeme olup, beton içerisinde üç boyutlu homojen dağılım sağlayan, servis ve tasarım yükleri altında taşıma kapasitesini artırmaktadır. Ayrıca çalışmada kullanılan fiber, eleman içinde sağladığı homojen dağı̆ım sayesinde, eleman oluşacak çatlakların kontrolünü de yapmaktadır. Makro Fiber diğer sentetik liflerden farklı olarak \%5 oranına kadar nemi bünyesine alabilme kabiliyetine sahiptir. Fiberin nem tutma özelliğinden dolayı, özellikle taze beton aşamasında nemi tutmaktadır [23].

Beton prizini almaya başladığında fiber malzeme; elemanın hidratasyonu için gerekli olan nemi geri vererek, elamanda içten kürleme etkisi yapmaktadır. Böylece, elemanda ısı ve rötreden dolayı oluşan çatlakların oluşumu minimize ederek yapısal bütünlük sağlamaktadır [23]. Fiber malzeme oranı, gereksinimlerine bağlı olarak, genellikle $2-10 \mathrm{~kg} / \mathrm{m}^{3}$ aralığında değişmektedir. Sentetik fiber malzemesine ait mekanik özellikleri Tablo 1 'de sunulmuştur.

Tablo1. Fiber donatı teknik özellikleri [23]

\begin{tabular}{ll}
\hline \multicolumn{1}{c}{ Fiber } & Karakteristik Özellikler \\
\hline Ham madde & Mod. Ed. Poliamid 6.6 \\
Özgül ağırlık $\left(\mathbf{g r} / \mathbf{c m}^{3}\right)$ & 1.14 \\
Uzunluk $(\mathbf{m m})$ & 54 \\
Çap $(\mathbf{m m})$ & 0.55 \\
Çekme gerilmesi (MPa) & 900 \\
Alkali direnci & Çok iyi \\
Korozyon Direnci & Çok iyi \\
Erime sıcaklığı $\left[{ }^{\circ} \mathbf{C}\right]$ & 260 \\
Fiber adedi $/ \mathbf{~ k g}$ & 88200 \\
\hline
\end{tabular}




\begin{tabular}{|c|c|c|}
\hline & $\begin{array}{l}\text { BŞEÜ Fen Bilimleri Dergisi } \\
7(2), 850-862,2020\end{array}$ & $\begin{array}{r}\text { BSEU Journal of Science } \\
\text { DOI: } 10.35193 / \text { bseufbd. } 709099\end{array}$ \\
\hline & & 58-7575 (http://dergipark.gov.tr/bseufbd) \\
\hline
\end{tabular}

Kullanılan fiber malzemenin ana ham maddesini oluşturan Poliamid 6.6, yüksek sertlik derecesine sahip ve mukavemeti yüksek bir malzeme olup, 1sı etkisi ile oluşacak deformasyonlara karşı da dirençlidir. Ayrıca çok yüksek eğilme ve çekme dayanımına sahip, tekrarlı gerilme-șekildeğiştirme ve ani darbe yüklerine karșı yüksek dirence sahip, her tür yük altında çalışmaya uygun, düşük sürtünme katsayısına sahip plastik esaslı bir malzemedir. Sentetik fiber özellikle mukavemet, sertlik ve yorulma direnci gibi mekanik özelliklerini güçlendirmek amacıyla elastomer ve cam elyafla takviye edilmektedir.

Çalışmada fiber değişiminin beton basınç dayanımına etkisini araştırmak amacıyla, öncelikle aynı şartlar altında hazırlanmış dört farklı beton sınıfından lif katkısız, $2 \mathrm{~kg} / \mathrm{m}^{3}(\% 0.08) \mathrm{ve} 8 \mathrm{~kg} / \mathrm{m}^{3}(0.32)$ oranında lif katkılı silindir numuneler hazırlanmıştır. Kalıplar $\mathrm{d}=100 \mathrm{~mm}$ ve $\mathrm{h}=200 \mathrm{~mm}$ boyutunda olup, standartlarda belirtilen $\mathrm{h} / \mathrm{d}=2$ oranını karşılamaktadır. Deneysel çalışmada, C20, C25, C30, C35 dört farklı dayanıma sahip beton numuneler hazırlanarak basınç deneyleri yapılmış, sonuçlar sonlu eleman modelindeki deformasyon değişimi ile karşılaştırılmıştır.

Çalışmada kullanılan beton malzemeleri karışım oranları Tablo 2'de verilmiştir. Karışımdaki su oranı yaklaşık bir oran olup kumun su içeriğine göre değişmektedir. Kum ve agrega granülometrisi Tablo 3'de verilmiştir.

Tablo 2. Beton karışım oranları

\begin{tabular}{ccccc}
\hline $\begin{array}{c}\text { Ağırlıkça Oran } \\
(\%)\end{array}$ & Çimento & Kum & Agrega & Su \\
\cline { 2 - 5 } & 15 & 35 & 40 & 10 \\
\hline
\end{tabular}

Tablo 3. Agrega ve kum granülometrisi

\begin{tabular}{cccc}
\hline \multicolumn{2}{c}{ Agrega } & \multicolumn{2}{c}{ Kum } \\
\hline $\begin{array}{c}\text { Elek } \\
\text { Büyüklü̆ğü } \\
(\mathbf{m m})\end{array}$ & $\begin{array}{c}\text { Kümülatif } \\
\text { Kalan } \\
(\boldsymbol{\%})\end{array}$ & $\begin{array}{c}\text { Elek } \\
\text { Büyüklüğ̈̈ } \\
(\mathbf{m m})\end{array}$ & $\begin{array}{c}\text { Kümülatif } \\
\text { Kalan } \\
(\boldsymbol{\%})\end{array}$ \\
\hline 20 & 0 & 4 & 0 \\
16 & 13 & 2 & 8 \\
12.5 & 22 & 1 & 28 \\
10 & 62 & 0.5 & 52 \\
4.75 & 73 & 0,25 & 80 \\
4 & 100 & 0,063 & 100 \\
\hline
\end{tabular}

\section{DENEYSEL ÇALIŞMA}

Sakarya Üniversitesi İnşaat Mühendisliği Laboratuvarlarında 12 adet $100 \mathrm{~mm} \times 200 \mathrm{~mm}$ ebatlarında silindir şeklinde lif katkısız ve farklı oranda lif katkılı numuneler hazırlanmış; priz hızlandırıcı, akışkanlaştırıcı vb. katkı maddeleri kullanılmamıştır. Silindirik deney numuneleri TS EN 12350-1 [24], TS EN 12390-1 [25], TS EN 12390- 2 [26], TS EN 12390- 3 [27] ve TS EN 12390-4 [28] standartlarına uygun olarak laboratuvar ortamında hazırlanmıştır. Deneysel çalışma kapsamında deney numunelerinden 3 seri hazırlanmış, farklı zaman aralıklarında eksenel basınç deneyine maruz bıralıkmıştır.

Dayanım testi bilgisayar kontrollü, hidrolik yüklemeli, TS EN ISO 6892-1 [29] uygun, malzeme test yazılıml, 300 ton kapasiteli, $\pm 1 \% \mathrm{~mm} \pm 0.2 \% \mathrm{~mm}$ deplasman ölçüm hassasiyetli, $250 \mathrm{~mm}$ 'lik hidrolik piston stroğuna sahip, 1/300000 kuvvet ölçüm rezilasyonlu hidrolik universal test cihazı ile yapılmıştır [30] (Şekil 1a).

Test cihazı, her deney öncesinde temizlenerek deneyler gerçekleştirilmiştir. Böylece, hidrolik test cihazından numuneye etki edebilecek olan eksantrik yükleme engellenmiştir.

Dökümden bir gün sonra kalıptan çıkarılan ve 28 gün boyunca kür havuzunda bekletilerek piriz alması sağlanan lif katkılı ve katkısız silindir beton numuneler, basınç yüklemesi altında incelenmeden önce, kürden çıkarılıp bir gün kurumaya bırakılmıştır. Basınç yükünün beton numunelere üniform olarak dağılımını sağlamak 
için $\% 70$ sarı kükürt ve $\% 30$ grafit tozunun $300{ }^{\circ} \mathrm{C}$ de eritilmesi ile elde edilen eriyik yardımıyla pürüzsüz bir yüzey oluşturarak numunelerin yük verilecek yüzeylerine kükürt başlıklar yapılmıştır (Şekil 1b, Şekil 1c). Lif katkısız ve farklı oranda lif ilave edilerek hazırlanan numunelere, yükleme hızı, dakikada 4mm olacak şekilde basınç yüklemesi uygulanmıştır [2]. Numunelerin deney öncesi ve deney sonrası görüntüleri Şekil 2'de verilmektedir. Buna göre kırılma türleri literatürdeki Feng Shi ve arkadaşları tarafından [31] yapılan çalışmada gözlenmiş olan kırılma şekilleri ile uyumludur. Basınç etkisi altında fiber donatı takviyeli betonlar öngörülen kırılma davranışları sergilemişlerdir.

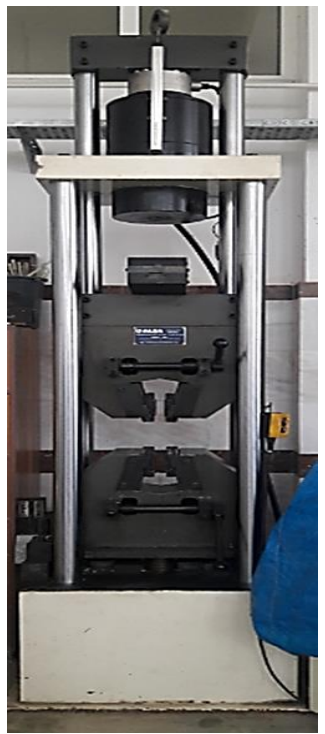

(a)

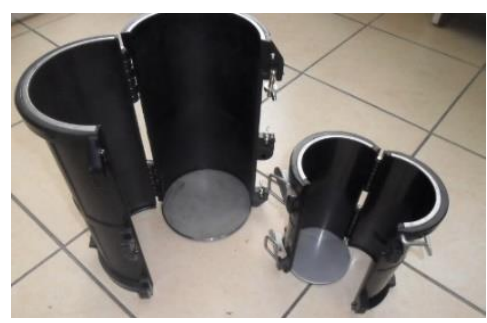

(b)

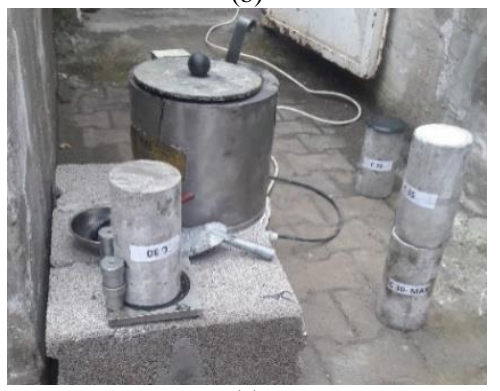

(c)

Şekil 1. (a) hidrolik test cihazı, (b) Numune kalıpları, (c) kükürt kazanı

\section{SONLU ELEMAN MODELİ}

Kompozit elemanın basınç etkisi altındaki davranışını incelemek amacıyla, sonlu eleman yazılımı Abaqus/Standart kullanılarak, deneysel çalışmadaki numuneleri yansıtan üç boyutlu sonlu eleman modeli hazırlanmıştır. Modellemede, doğru malzeme modelinin seçilmesine yönelik olarak ABAQUS sonlu eleman kütüphanesinde tanımlı olan, basınç yüklemesi altında deney numunesinde oluşan ezilme ve çatlak davranışını en ideal şekilde yansıtan, Beton Plastikleşme Hasar Modeli (Concrete Damage Plasticity Model-CDP) kullanılmıştır [32,33]. CDP malzeme modeli fiber ile güçlendirilmiş beton elemanların modellemesinde yaygın olarak kullanılmaktadır [34,35]. Doğrusal olmayan analizlerde, CDP malzeme modelindeki ezilme durumunu tanımlamak için, elemanın eksenel basınç altındaki gerilme-şekil değiştirme eğrileri kullanılmıştır (Şekil 3). 


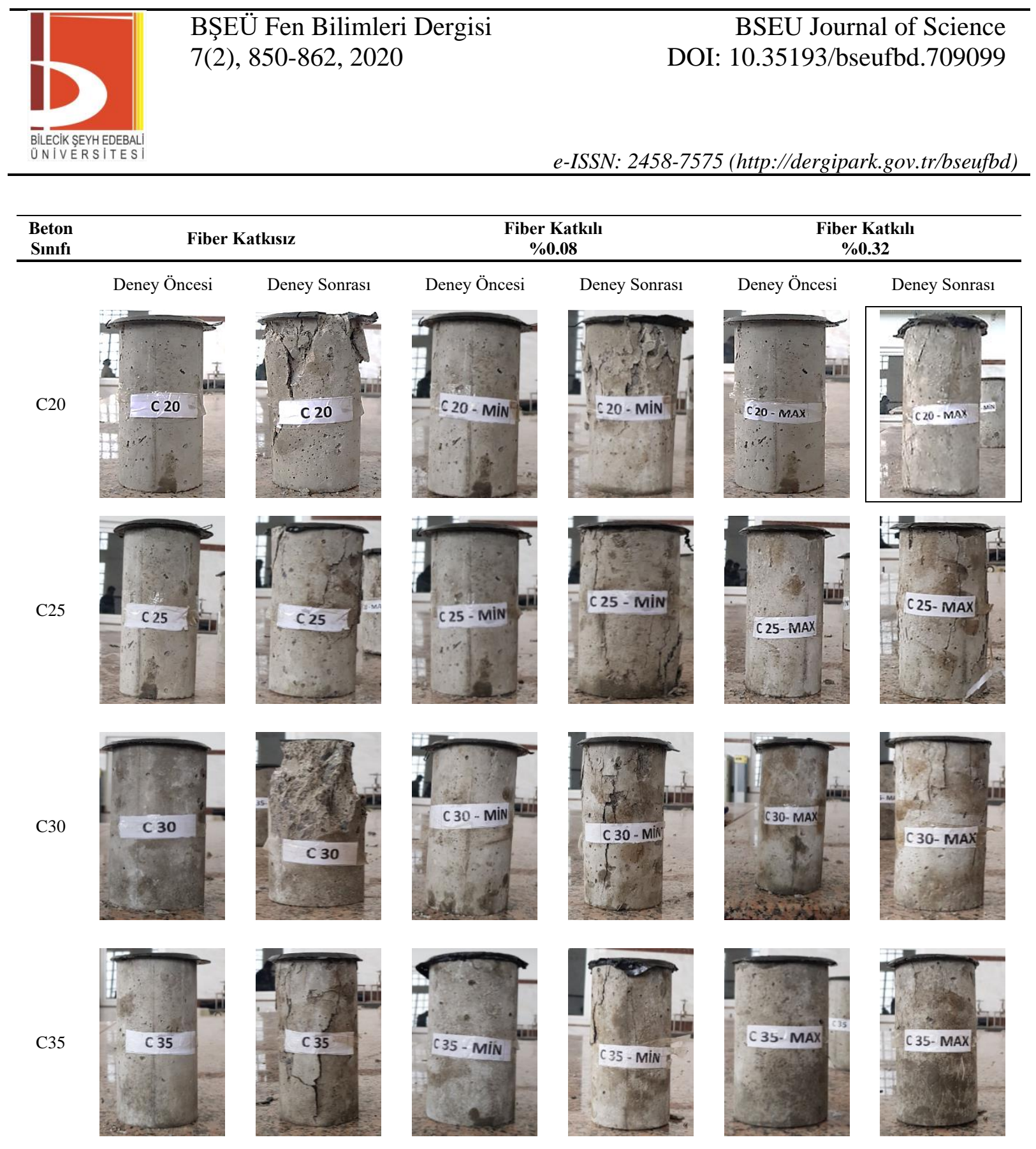

Şekil 2. Beton numunelerin deney öncesi ve deney sonrası görünüşleri 


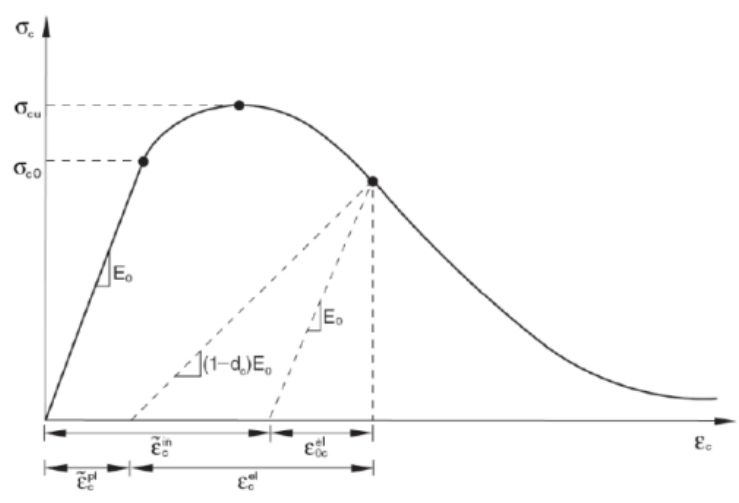

(a)

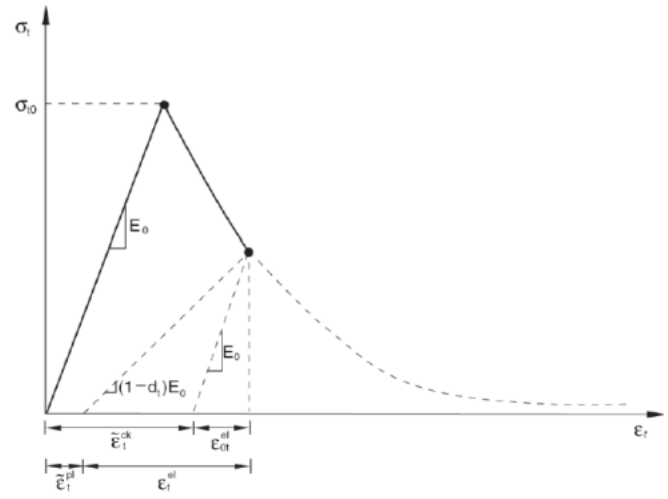

(b)

Şekil 3. Betonun (a) eksenel basınç ve (b) çekme altında CDP modeline gerilme-şekil değiştirme ilişkisinin tanımlanması [33,34]

Sonlu eleman parçacık modeli olarak, ABAQUS kütüphanesinden, üç boyutlu sürekli katı ve sekiz düğüm noktalı C3D8R eleman tipi seçilmiştir. Bu eleman düğüm noktaları köşelerinde olan elemanlar olup her yönde doğrusal enterpolasyon kullanır ve genellikle doğrusal elemanlar veya birinci dereceden elemanlar olarak adlandırılır. C3D8R eleman tipi genellikle üç boyutlu katı cisimlerin çözümünde kullanılmaktadır. Ayrıca söz konusu elemanın CDP malzeme modeline uygun olarak çatlak ve hasar oluşumunu simule eden en uygun elemanlardan biridir. Analiz sırasında kullanılan zamanı minimize etmek için, yine ABAQUS kütüphanesinden azaltılmış integrasyon yöntemi kullanılmıştır. Bu yöntem, seçilen sonlu eleman parçacık modelinde düğüm noktası sayısının fazla olması durumunda, düğüm noktası sayısının parçacık orta noktasında tek noktaya indirgenerek, çok düğüm noktalı parçacık analiz sonuçları ile yaklaşık eşit sonuç vermektedir. Sonlu eleman model, 55693 düğüm noktası ve 51840 sonlu elemandan oluşmaktadır. Oluşturulan modelin sonlu eleman ağ sıklığı (mesh) Şekil 4 (a), sınır şartları ve yükleme durumu Şekil 4 (b) ve eleman tipi Şekil 4 (c)'de verilmiştir.

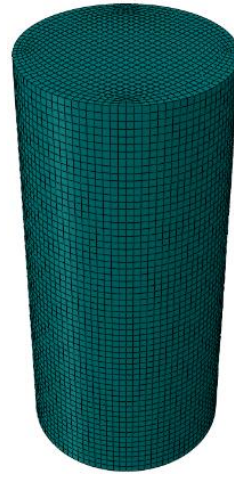

(a)

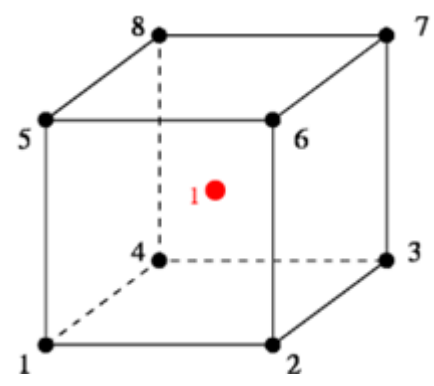

(b)

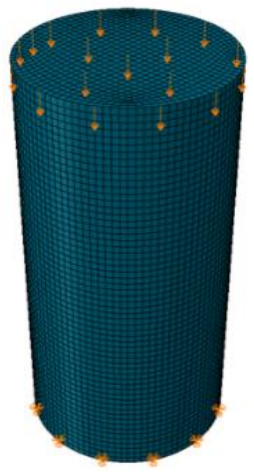

(c)

Şekil 4. (a) CTP malzeme modeli, (b) C3D8R eleman tipi, (c) sınır şartları

\section{VI.BULGU VE TARTIŞMA}

\section{A. Sonuçlar ve Tartışma}

Çalışma kapsamında hazırlanan numuneler tek doğrultuda basınç deneyine tabi tutularak lif katkısız ve farklı oranda lif katkılı 12 adet olacak şekilde hazırlanmıştır. Deney sonucu elde edilen gerilme ve eksenel kuvvet değerleri ile eksenel yük taşıma kapasitelerindeki değişim oranları Tablo 4 ve Şekil 5 'te gösterilmiştir. Tablo 4 'den görüleceği üzere, deneyler sonucunda lif katkısız C20, C25, C30 ve C35 beton sınıfı deney numuneleri beklenen 
beton dayanımından daha yüksek dayanım sergilemiştir. Bu sonuçlar, üretici firma tarafından standartlara uygun hatta standartların üstünde bir kaliteye sahip beton üretildiğinin göstergesi olarak belirtilebilir.

Deney numunelerindeki lif katkı oranı $2 \mathrm{~kg} / \mathrm{m}^{3}$ olarak ayarlanan numunelerin basınç dayanımı incelendiğinde, beton basınç dayanımlarının lif katılmamış numune dayanımlarından \%7 ile \%10 aralığında değişen değerlerde düşüş olduğu gözlenmiştir. Beton yük taşıma kapasitesindeki düşüş oranı, ortalama bir değere dönüştürülürse, dayanımdaki düşüşün fibersiz betonun yük taşıma kapasitesine oranı yaklaşık \%8 olduğu söylenebilir.

Tablo 4. Deney numunelerinin kuvvet ve gerilme değerleri

\begin{tabular}{|c|c|c|c|c|c|}
\hline $\begin{array}{l}\text { Beton } \\
\text { Sinıfi }\end{array}$ & $\begin{array}{c}\text { Fiber Oranı } \\
\text { (Ağırlıç̧a \%) }\end{array}$ & $\begin{array}{l}\text { Numune } \\
\text { Kodu }\end{array}$ & $\begin{array}{c}\text { Kuvvet } \\
(\mathrm{kN})\end{array}$ & $\begin{array}{l}\text { Gerilme } \\
\text { (MPa) }\end{array}$ & $\begin{array}{c}\text { Eksenel Yük Taşıma Kapasitesindeki } \\
\text { Azalma }(\%)\end{array}$ \\
\hline \multirow{3}{*}{$\mathrm{C20}$} & 0 & $\mathrm{C} 20$ & 252.7 & 32.2 & 0 \\
\hline & 0.08 & $\mathrm{C} 20 \# 2$ & 235.6 & 30.0 & 7 \\
\hline & 0.32 & $\mathrm{C} 20 \# 8$ & 227.8 & 29.0 & 10 \\
\hline \multirow{3}{*}{$\mathrm{C} 25$} & 0 & $\mathrm{C} 25$ & 259.2 & 33.0 & 0 \\
\hline & 0.08 & $\mathrm{C} 25 \# 2$ & 233.3 & 29.7 & 10 \\
\hline & 0.32 & $\mathrm{C} 25 \# 8$ & 200.3 & 25.9 & 22 \\
\hline \multirow{3}{*}{ C30 } & 0 & C30 & 302.4 & 38.5 & 0 \\
\hline & 0.08 & C30\#2 & 278.8 & 35.5 & 8 \\
\hline & 0.32 & C30\#8 & 234.8 & 29.9 & 22 \\
\hline \multirow{3}{*}{ C35 } & 0 & C35 & 361.3 & 46.0 & 0 \\
\hline & 0.08 & $\mathrm{C} 25 \# 2$ & 333.8 & 42.5 & 8 \\
\hline & 0.32 & C35\#8 & 299.2 & 38.1 & 17 \\
\hline
\end{tabular}

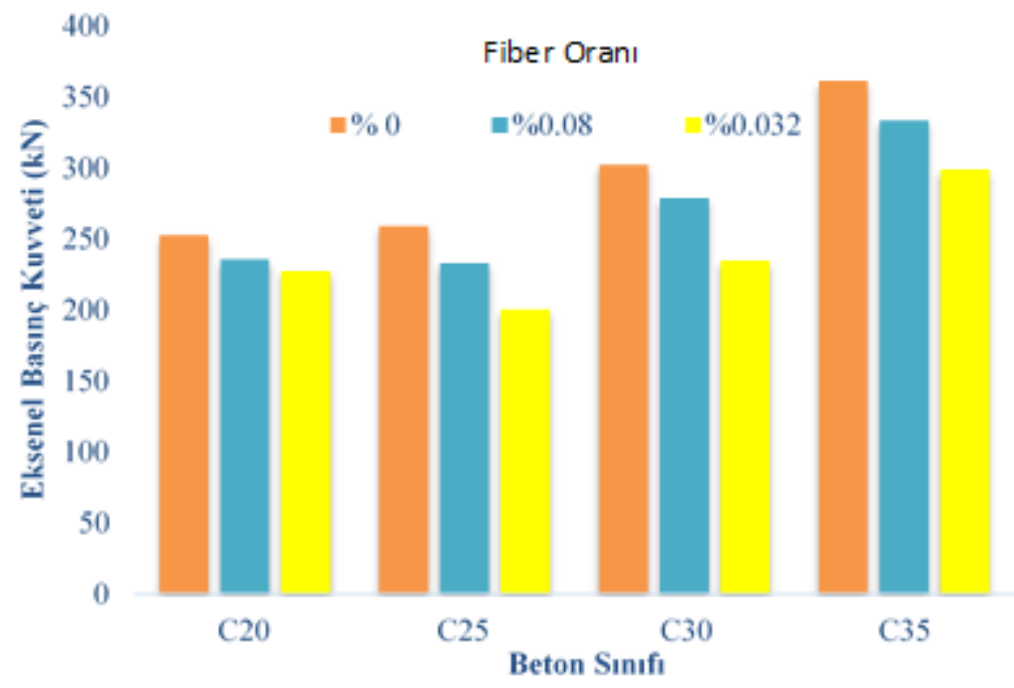

Şekil 5. Fiber oranının beton basınç dayanımı üzerine etkisi

Çalışmada kullanılan her beton sınıfı için lif katkısız, ağırlıça \%0.08 ve \%0.32 oranında lif katkılı olarak üretilen silindir numunelerin tek eksenli basınç deneyi sonucu elde edilen gerilme-boy değişim oranı grafikleri Şekil 6'da sunulmuştur. 


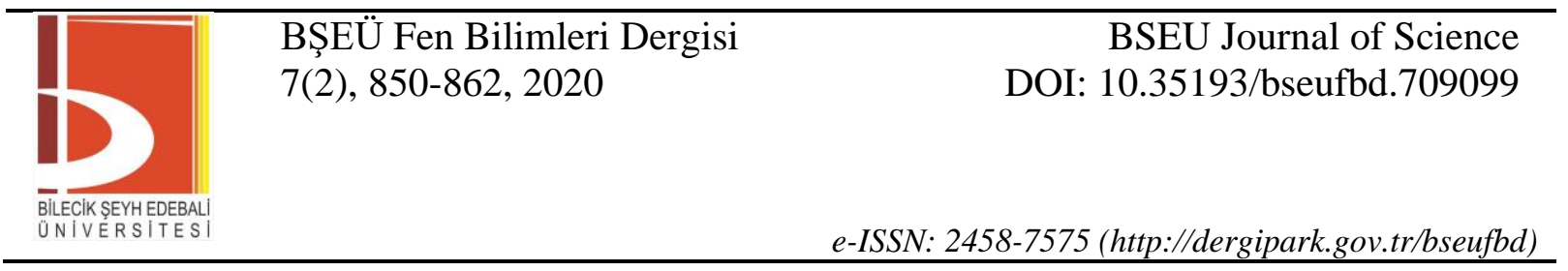

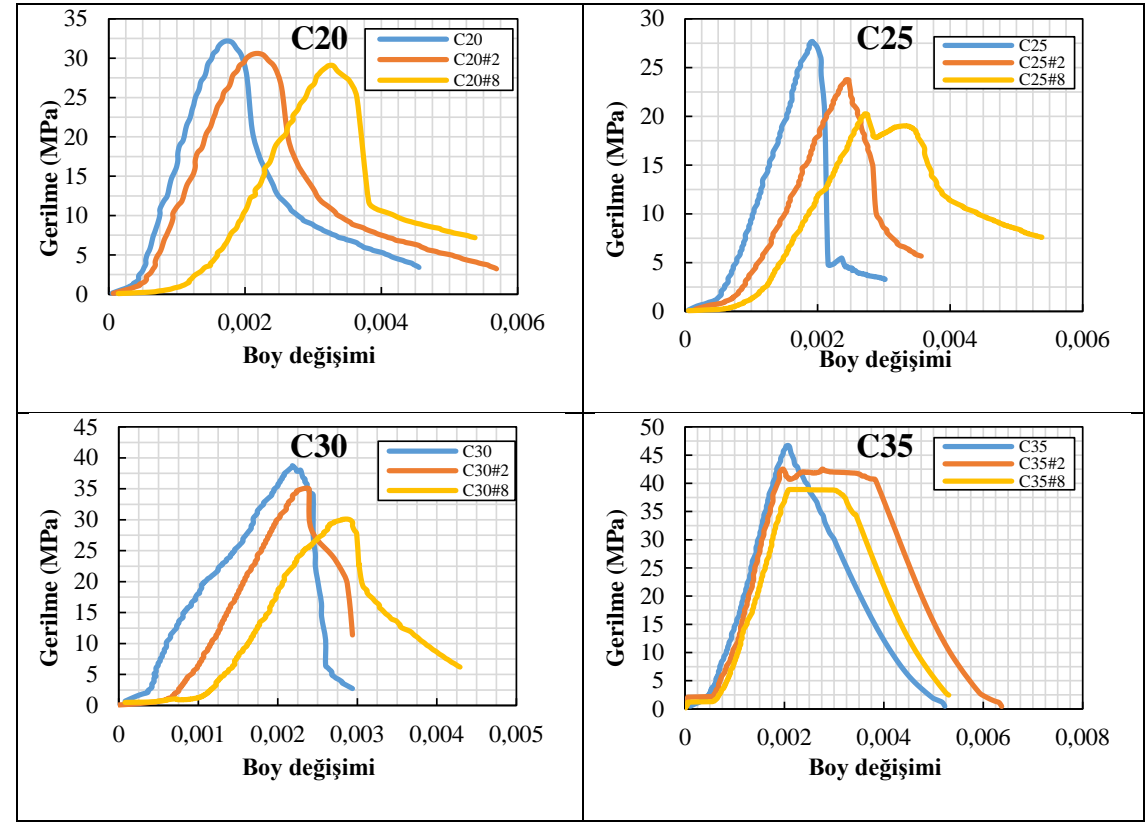

Şekil 6. Gerilme-boy değişim ilişkisi

Deney sonucu elde edilen gerilme-boy değişimi ile, C3D8R eleman tipi ve CDP malzeme modeli kullanılarak sonlu eleman modeli tanımlanmış ve analiz sonucu elde edilen kırılma ve çatlama şekilleri deneysel çalışma sonunda silindir beton numunelerde gözlenen kırılma ve çatlama şekilleri ile karşılaştırılmıştır.

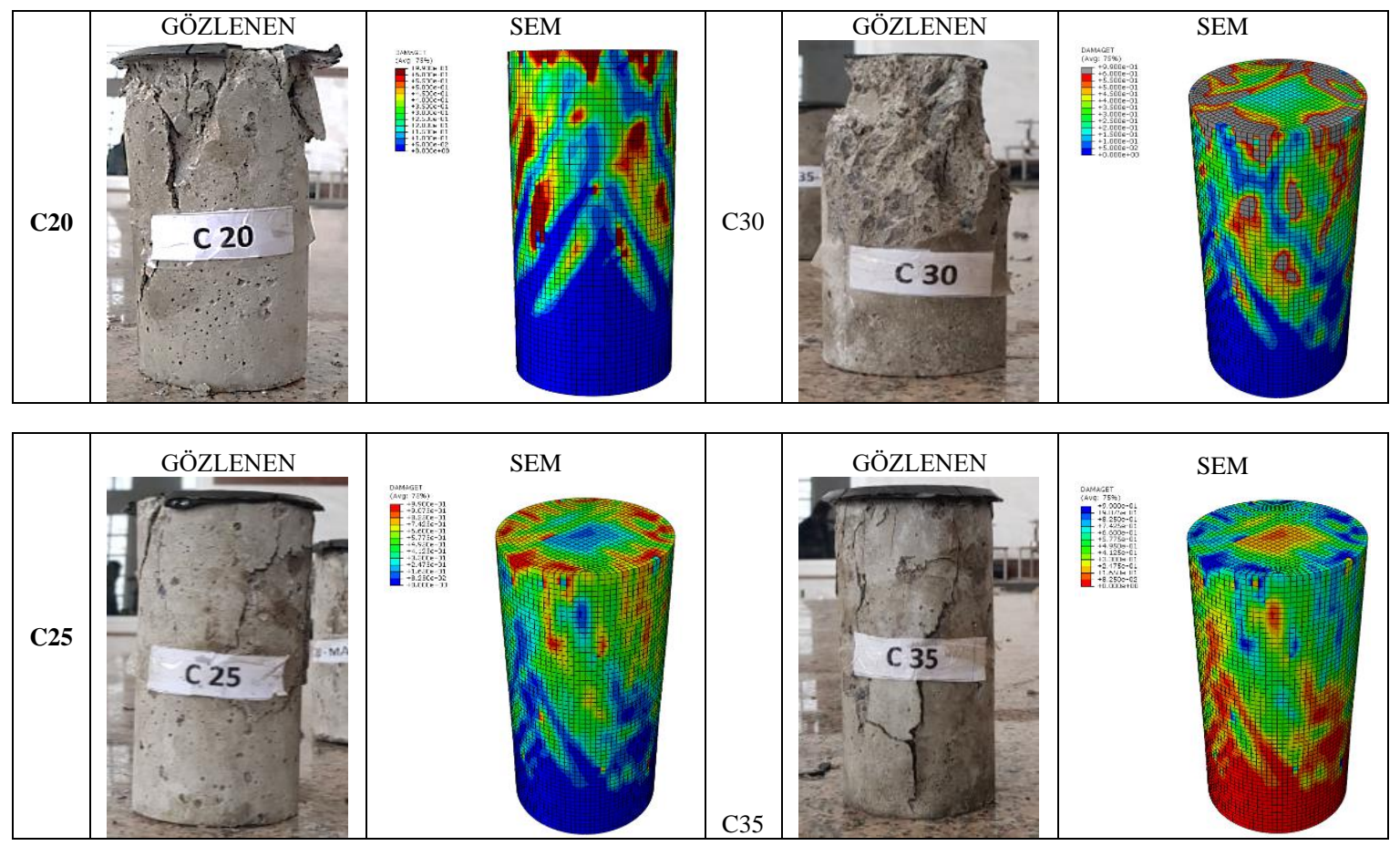

Şekil 7. Numunelerin deneysel sonucu ile sonlu eleman hasar durumunun karşılaştırılması 
Numunelerin deney sonrası kırık-çatlak hasarı görüntüleri ile sonlu eleman model analizinden elde edilen hasar durumu görüntüleri Şekil 7'de karşılaştırılmıştır. Numunelerin gerek deneysel gerekse sonlu eleman analiz sonucu elde edilen sergiledikleri hasar davranışı büyük oranda benzerlik göstermektedir. Bu durum sonlu eleman analizinde kullanılan eleman tipi ve malzeme modeli tercihini doğrulamaktadır.

\section{SONUÇ ve ÖNERILER}

Farklı dayanıma sahip beton numunelere, farklı oranda fiber ilave edilmesinin, beton basınç dayanımına etkileri deneysel olarak incelenmiş ve Abaqus/Standart yazılımı ile oluşturulan matematik modelinin sonlu eleman analizi sonuçları deneysel veriler ile karşılaştırılmıştır Farklı beton sınıflarına farklı oranda fiber donatı takviyesi ilave edilerek oluşturulmuş numuneler basınç yüklemesi altında incelendiğinde, fiber donatı takviyeli kompozit malzemeler ile ilgili olarak aşă̆ıdaki sonuçlar elde edilmiş̧ir.

Deney numunelerinin grafikleri incelendiğinde, fiber takviyesinin şekil değiştirme kapasitesine katkı sağladığı görülmüştür. Dört farklı beton sınıfının deneysel grafikleri incelendiğinde, numunelerin maksimum eksenel yük kapasitesine ulaştıktan sonra dahi, beton etkin şekil değiş̧irme kapasitesi ile enerji sönümlemeye devam ettiği görülmüştür. Beton dayanımındaki değişimin, şekil değiştirme davranışına etkileri irdelenecek olunursa, özellikle C35 beton sınıfindaki fiber katkılı her iki numunenin maksimum basınç dayanımında bir sahanlık bölgesine sahip olması, fiber donatının yüksek dayanımlı beton ile beraber uyumlu çalıştığının bir göstergesi olarak belirtilebilir.

Deney sonunda numuneler incelendiğinde, fiber ilave edilmeyen dört farklı beton numunesi maksimum basınç dayanımına eriştikten sonra bünyesinde oluşan deformasyonların gözle görülebilir düzeydedir. Buna karşın, her dört beton sınıfı için üretilmiş fiber katkııı beton numuneleri, maksimum basınç dayanımına eriştikten sonra dahi bünyelerinde gözle görülebilir çatlak ve kırı hasarları gözlenmemiştir. Özellikle aynı beton sınıfına ait fiberli ve fibersiz numunelerin gerilme-boy değişimi incelendiğinde, fiber katkılı elemanların daha sünek davrandığı, ayrıca fibersiz numune ile kıyaslandığında çatlama, dağılma ve dökülmenin baskın şekilde olduğu görülmemiştir. Sentetik fiber donatının yük altında oluşan yapısal çatlaklara karşı etkili bir çözüm sunduğu ve etkin çatlak kontrolünü her noktada sağladığı gözlenmiştir.

İncelenen tüm beton sınıflarında fiber oranı ağırlıkça \%0.08'den \%0.32'ye çıkarıldığında, beton basınç dayanımının düştüğü görülmüştür. Lif katkı oranı ağırlıkça $\% 0.08$ olarak ayarlanan numunelerin basınç dayanımı incelendiğinde, beton basınç dayanımlarının lif katılmamış numune dayanımlarına oranla ortalama \%8 azaldığı söylenebilir. Lif katkı oranı ağıllıkça \%0.32 olarak ayarlanan numuneler de benzer durum gözlemlenmekle birlikte dayanımdaki bu düşüş oranının daha da artarak ortalama \%18'e yükseldiği gözlenmektedir. Sonuç olarak fiber miktarının artmasının belli bir orandan sonra beton basınç dayanımını düşürdüğ̈ görülmektedir.

Fiber malzemesinin uygulanmasında; beton hazırlandıktan sonra minimum $5 \mathrm{dk}$ trans-mikserin son hızında karıştııılması gerekmektedir. Ancak yapılan deneysel çalışma kapsamında mevcut laboratuvar olanakları çerçevesinde, hazırlanan betonun içine konulan fiber elle karıştırılarak deney numuneleri oluşturulmuştur. Farklı dayanımda hazırlanmış numunelerin eksenel basınç kuvvetine tabi tutulmaları sonucu, dayanım değerlerinin beklenenden fazla olmasının bu duruma bağlı olabileceği öngörülmektedir.

\section{KAYNAKLAR}

[1] Akman, M. S. (2003). Yapı Malzemelerinin Tarihsel Gelişimi. TMH - Türkiye Mühendislik Haberleri Sayı $426-2003 / 4$

[2] Ağcakoca, E., \& Yaman, Z. (2018). Effect On Pressure Resistance Of Minimum Ratio Fiber Supply In Concrete Numbers. In 2nd International Symposium on Natural Hazards and Disaster Management, Sakarya University Culture and Congress Center, Sakarya-Turkey.

[3] Yenidünya, E. (2013). Farklı maksimum sicakllk değerleri altında buhar kürü uygulamasının çelik lifli betonların mekanik dayanımına etkisi. Doktora Tezi, Selçuk Üniversitesi Fen Bilimleri Enstitüsü, Konya. 
[4] Yildiz, S., \& Ulucan, Z. (2008). Beton Borularda Cam Lif Katkısının Tepe Yük Dayanımına Etkisinin Araştırılması. Gazi Üniversitesi Mühendislik-Mimarlık Fakültesi Dergisi, 23:2.

[5] Çelikten, S. (2014). Çelik Fiber Iç̧eren Dayanımlı Beton Özellikleri Üzerine Metakaolin ve Öğ̈̈tülmüş Pomzanın Etkisi, Yüksek Lisans Tezi, Niğde Üniversitesi, Fen Bilimleri Enstitüsü, Niğde.

[6] Avar, D. (2006). Karma Lifli Betonların Mekanik Davranışına Buhar Kürü Etkisi, Doktora tezi, İstanbul Teknik Üniversitesi Fen Bilimleri Enstitüsü, İstanbul.

[7] Eruslu, S.Ö. (2008). Klsa Elyaf Takviyeli Kompozit Plaklarda Titreşim Analizi, Doktora Tezi, Trakya Üniversitesi Fen Bilimleri Enstitüsü, Edirne.

[8] Eren, A., \& Soyarslan, D. (2016). Tekstil Malzemelerinin İnşaat Mühendisliği Uygulamaları, Mehmet Akif Ersoy Üniversitesi Fen Bilimleri Enstitüsü Dergisi, 7(Özel 1), 29-34.

[9] Agcakoca, E., \& Biyiklioglu, E. (2020). Experimentally and Numerically Investigating the Performances of Aramid Fiber-Reinforced Steel Beams Under Impact Loadings. Arabian Journal For Science And Engineering.

[10] Hüsem, M., \& Demir, S. (2013). Çelik ve Polipropilen Liflerin Geleneksel ve Yüksek Performansli Betonlarda Kirilma ve Çatlak Gelişimine Etkisi. Engineering Sciences, 8:4, 182-193.

[11] Özşahin, B., Mülayim, B., ve Arkoç, O. (2015). Betonarme Yapı Elemanlarında Lif Takviyeli Polimerlerin Kullanımı. 9. Uluslararası Sinan Sempozyumu, 21-22 Nisan, Türkiye, 109-115.

[12] Çelik, K.V., \& Karaşin, H. (2014). Karbon elyaf ile betonun güçlendirilmesi. Dumlupınar Üniversitesi Mühendislik Fakültesi Dergisi, 5(1), 1-11.

[13] Taşdemir, M., Bayramov, F. (2012). Yüksek performanslı çimento esaslı kompozitlerin meri kanik davranışı. İstanbul Teknik Üniversitesi Dergisi, Aralık Cilt 1; Sayı 2, Sayfa 125-144.

[14] Kim, H., Kim, G., Gucunski, N., Nam, J., \& Jeon, J. (2015). Assessment of flexural toughness and impact resistance of bundle-type polyamide fiber-reinforced concrete. Composites Part B: Engineering, 78, 431-446.

[15] Kim, H., Kim, G., Lee, S., Son, M., Choe, G., \& Nam, J. (2019). Strain rate effects on the compressive and tensile behavior of bundle-type polyamide fiber-reinforced cementitious composites. Composites Part B: Engineering, 160, 50-65.

[16] Yildizel, S. A., Tayeh, B. A., \& Calis, G. (2020). Experimental and modelling study of mixture design optimisation of glass fibre-reinforced concrete with combined utilisation of Taguchi and Extreme Vertices Design Techniques. Journal of Materials Research and Technology.

[17] Aydin, A. C., Yaman, Z., Ağcakoca, E., Kiliç, M., Maali, M., \& Dizaji, A. A. (2019). CFRP Effect on the Buckling Behavior of Dented Cylindrical Shells. International Journal of Steel Structures, 1-11.

[18] Maali, M., Kılıç, M., Yaman, Z., Ağcakoca, E., \& Aydın, A. C. (2019). Buckling and post-buckling behavior of various dented cylindrical shells using CFRP strips subjected to uniform external pressure: comparison of theoretical and experimental data. Thin-Walled Structures, 137, 29-39.

[19] Nasery, M. M., Hüsem, M., Okur, F. Y., \& Altunişik, A. C. (2020). Damage effect on experimental modal parameters of haunch strengthened concrete-encased composite column-beam connections. International Journal of Damage Mechanics, 29(2), 297-334 
[20] Hüsem, M., Nasery, M. M., Okur, F. Y., \& Altunişik, A. C. (2018). Experimental evaluation of damage effect on dynamic characteristics of concrete encased composite column-beam connections. Engineering Failure Analysis, 91, 129-150.

[21] EN, B. 14889-2, (2006). Fibres for concrete-Part, 2.

[22] ASTM C1116/C1116M-10a (2015). Standard Specification for Fiber-Reinforced Concrete

[23] http://www.kordsa.com/kratos/assets/kratosbrosurtr.pdf/ 14:00 / (15.02.2018)

[24] TS EN 12350-1, (2019), Beton - Taze beton deneyleri - Bölüm 1: Numune alma ve yaygın kullanılan aygıtlar.

[25] TS EN 12390-1, (2014), Beton - Sertleşmiş beton deneyleri - Bölüm 1: Deney numunesi ve kalıplarının şekil, boyut ve diğer özellikleri.

[26] TS EN 12390-2, (2019), Beton - Sertleşmiş beton deneyleri - Bölüm 2: Dayanım deneylerinde kullanılacak deney numunelerinin hazırlanması ve küre tabi tutulması.

[27] TS EN 12390-3, (2019), Beton - Sertleşmiş beton deneyleri - Bölüm 3: Deney numunelerinin basınç dayanımının tayin.

[28] TS EN 12390-4, (2019), Beton - Sertleşmiş beton deneyleri - Bölüm 4: Basınç dayanımı - Deney makinelerinin özellikleri.

[29] TS EN ISO 6892-1, (2020). Metalik malzemeler - Çekme deneyi - Bölüm 1: Ortam sıcaklığında deney yöntemi

[30] http://www.alsalab.com/hidrolik-universal-test-cihazi-utm3000.html / 13:00 / (15.02.2020)

[31] Feng S., Thong ,M. P., Hong, H., Yifei ,H., (2020). Post-cracking behaviour of basalt and macro polypropylene hybrid fibre reinforced concrete with different compressive strengths, Construction and Building Materials, Volume 26230 November 2020Article 120108

[32] George, J., Rama, J.K., Kumar, MS., \& Vasan, A. (2017). Behavior of Plain Concrete Beam subjected to Three Point Bending using Concrete Damaged Plasticity (CDP) Model. Materials Today Proceedings, 4:9, 9742-9746.

[33] Wu, WLJ.,(2017). A note on the ABAQUS Concrete Damaged Plasticity (CDP) model. In Civil, Architecture and Environmental Engineering (pp. 1301-1306). CRC Press.

[34] ABAQUS, Abaqus Manuals. version 2018. Providence, RI: Dassault Systèmes Simulia Corp, 2018. 